\title{
Community Pharmacists as Partners in Reducing Suicide Risk
}

\author{
Cortney M. Mospan, PharmD, BCACP, BCGP, Chris Gillette, PhD, \\ Jerry McKee, PharmD, MS, BCPP, and Stephanie S. Daniel, PhD
}

(J Am Board Fam Med 2019;32:763-767.)

Keywords: Community Medicine, Continuity of Patient Care, Mental Health, Pharmacists, Primary Health Care, Public Health, Suicidal Ideation, Suicide

Death by suicide is a significant public health problem, with deaths resulting from suicide increasing by $28 \%$ from 1999 to $2016 .{ }^{1}$ Of those whose died by suicide, $54 \%$ were not previously diagnosed with a mental health condition. ${ }^{1}$ Lack of a formal mental health diagnosis could be attributed to social stigma or limited access to health care. ${ }^{2}$ The United States Preventative Services Task Force (USPSTF) recommends periodic screening for depression in the general adult population, but only $2.25 \%$ to $5 \%$ of adults are screened by their primary care provider (PCP) in a given year. ${ }^{3-5}$ Increasing national focus on depression and suicide, including media reports of celebrity deaths and Logic's song, "1 to 800 to 273 to 8255" (National Suicide Prevention Hotline), highlights the importance of enlisting multiple health care providers at different points of access to help identify those who are struggling with mental health symptoms and suicidal ideation. $^{6-9}$

PCPs play an important role in screening for and identification of suicidal ideation, as they are

This article was externally peer reviewed.

Submitted 22 January 2019; revised 8 May 2019; accepted 9 May 2019.

From Wingate University School of Pharmacy, Wingate, NC (CMM); Department of Physician Assistant Studies, School of Medicine, Wake Forest University, Winston-Salem, NC (CG); Ballad Health - Woodridge Hospital, Johnson City, TN (JM); School of Medicine, Wake Forest University, Winston-Salem, NC (SSD)

Funding: none.

Conflict of interest: none declared.

Corresponding author: Cortney M. Mospan, PharmD, BCACP, BCGP, Wingate University Levine College of Health Sciences, 515 N. Main St Wingate, NC 28174 (Email: c.mospan@wingate.edu). one of most likely members of the health care team to have contact with a patient before an attempted suicide. Just $19 \%$ of patients have contact with a mental health provider in the month before attempting suicide, but $45 \%$ have contact with their PCP. ${ }^{10}$ Community pharmacists can also play an opportune role in assessing and identifying suicidal ideation in collaboration with PCPs and connecting patients with mental health care. Community pharmacists have more frequent contact with patients throughout the year; patients visit their PCP on average 4 times a year, while visiting their community pharmacy up to 35 times. ${ }^{11}$ With their accessibility, community pharmacists are poised to screen for, detect, and refer patients who may be at risk for mental health crisis. Figure 1 highlights the authors' proposed role for an interdisciplinary model for mental health screening and access. Although psychiatrists may be better equipped to provide the optimal initiation of care compared with PCPs or nonphysician mental health care providers, all providers must be utilized to address this need. ${ }^{12}$ Of patients seeking treatment in 2017, $20.3 \%$ reported unmet treatment needs. ${ }^{13}$

Community pharmacists play an important and unique role in the health care system. Patients have reported that their connections with their community pharmacists are critical in times when their prescribers are not available, and they are willing to engage with and share important health information with their community pharmacists. ${ }^{14}$ Previous literature has shown that community pharmacists are able to complete mental health screenings in practice and, therefore, play a vital role in identifying patients at risk. ${ }^{15-20}$ Patients' and other 
Figure 1. Flowchart of the initial patient recruitment process.
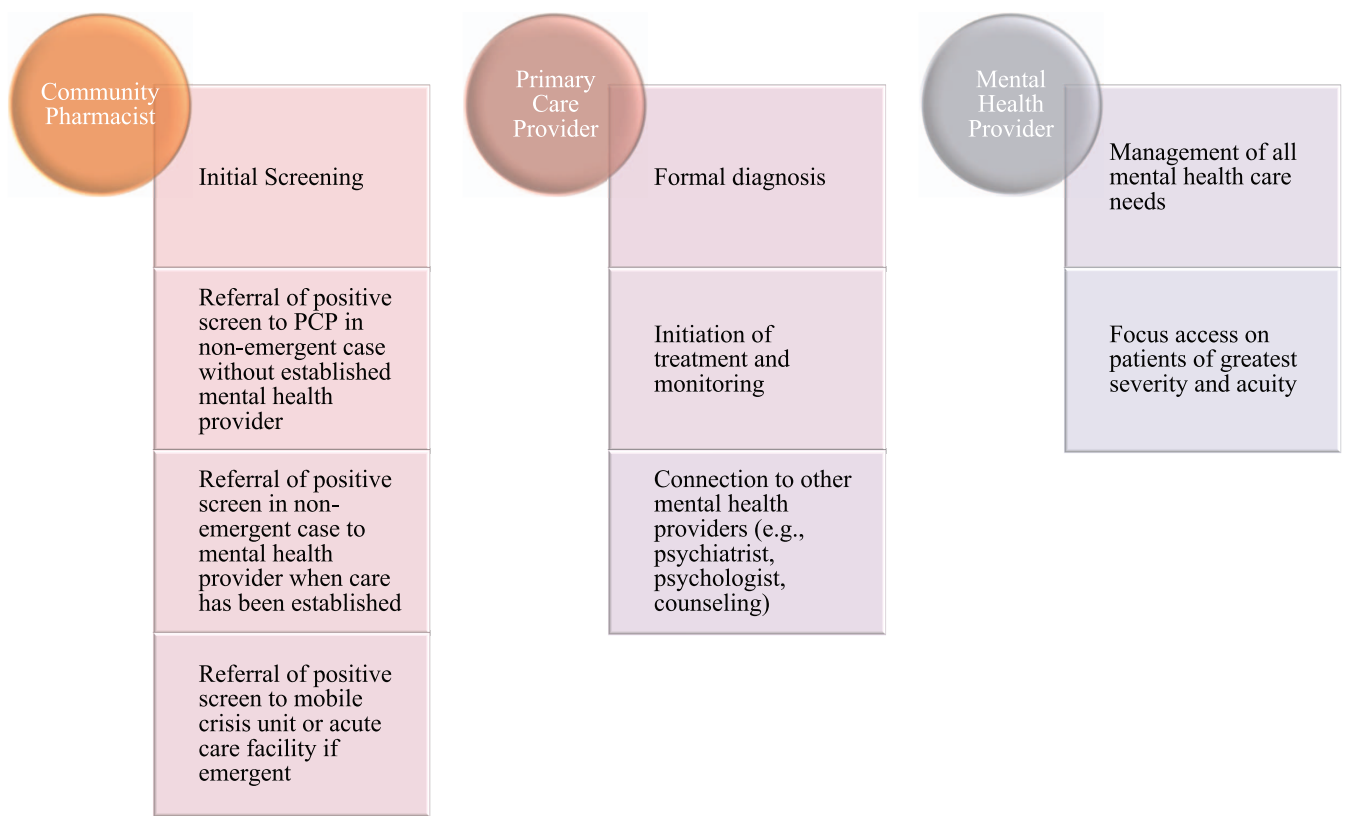

Connection to other mental health psychiatrist,

Referral of positive

crisis unit or acute

are facility if

health care providers' current lack of understanding of the pharmacist's place in the health care system may impede the uptake of a greater role of the community pharmacist in mental health care. However, there are indications that societal attitudes toward engaging with a community pharmacist on such topics may be evolving. A total of $91 \%$ of patients taking mental health medications reported being very comfortable going to community pharmacies and $83 \%$ feel they are treated with respect by their community pharmacist. ${ }^{21}$ Patients with mental health conditions have reported a relationship of trust with their pharmacist as a facilitator of communication about mental health needs, as it reduces fear of stigma. ${ }^{22}$

To further highlight why community pharmacists need to be engaged in mental health screening and monitoring of these conditions, a recent study by Qato et al. ${ }^{23}$ found that more than one-third of adults in the United States are currently taking medications that have the potential to cause depression. In addition, the prevalence of patients taking a drug with suicidal ideation as a potential adverse effect increased from $17 \%$ in 2005 to 2006 to almost $24 \%$ in 2013 to $2014 .{ }^{24}$ Lavigne $^{24}$ recently found that 125 Food and Drug Administrationapproved prescription drugs have suicidal ideation as a potential adverse effect and some of these are prescribed at high rates. Community pharmacists are in an ideal position to monitor patients who are currently prescribed medications that warrant monitoring for emerging signs for suicide risk or other mental health crisis.

Although community pharmacists are well-positioned to help with screening for suicidal ideation, engaging them more fully in this aspect of health care management is not without barriers. Examples of barriers for collaboration between PCPs and community pharmacists to address needs of patients with mental health issues include community pharmacists' lack of comfort and training in responding to mental health needs, low awareness of community resources available for patients who need assistance and support, stigma associated with mental health conditions, and lack of awareness of the potential role of the pharmacist. ${ }^{15,25,26}$ The authors have found lack of time to be another commonly reported barrier. Surprisingly, although lack of reimbursement has been reported as a barrier, it was ranked as 1 of the lowest of 12 barriers in a study among North Carolina pharmacists. ${ }^{27,28}$

Patients have also supported community pharmacists receiving training in suicide prevention, which would address some of the identified barriers. ${ }^{14}$ Sixteen programs are available for community pharmacists across the nation; however, Washington state is the only state that has a required suicide training program for pharmacists. ${ }^{29}$ Mental 
Health First Aid (MHFA) training could be an avenue to improve community pharmacists' confidence by preparing them to identify, understand, and respond to mental health needs. ${ }^{30} \mathrm{MHFA}$ is an evidence-based training that was developed by a mental health literacy expert. ${ }^{31}$ Training helps to build self-efficacy and confidence by increasing their mental health literacy, ability to recognize signs and symptoms of mental health crisis, appropriate responses to patients with suicidal thoughts, and referral processes and locations for patients. ${ }^{16}$ MHFA training is required for community pharmacy accreditation in Australia. ${ }^{32}$ For PCPs looking to collaborate with community pharmacists in suicide prevention, they may consider requiring their community pharmacist colleagues to complete this training.

PCPs interested in collaborating with community pharmacists for this public health need must ensure their collaborators are adequately prepared to respond to positive screens. USPSTF states depression, suicidal ideation, and other mental health screenings should only be undertaken when supports are available for proper diagnosis, treatment, and follow-up. ${ }^{3}$ PCPs must work with their community pharmacist colleagues to develop an agreeable algorithm for communication of findings and awareness of resources in their respective communities, particularly if the patient needs immediate crisis services. ${ }^{33}$ Furthermore, best practices still need to be identified for how community pharmacists should structure these screenings and interventions in a confidential manner. Research is also needed to identify how screening results should be communicated to PCPs for follow-up and intervention.

PCPs must help patients recognize the value of their community pharmacists in nondispensing health care roles. Although patients have reported a willingness to disclose self-harm with community pharmacists, they have reported some trepidation regarding community pharmacists' role in mental health. This could be due to concerns for stigma and judgment or ability for community pharmacy workflow to accommodate their needs, which were identified by Murphy et al. ${ }^{14}$ Lack of private counseling areas where other patients cannot overhear conversations may contribute to patient concerns. Community pharmacies should work to create comfortable and private counseling areas for these interventions. Some patients also admitted that they have never considered the role of their pharmacist in mental health care. ${ }^{14}$

Facilitators for this new role include the accessibility of the pharmacist, awareness campaigns tailored to patients and providers to educate each about enhanced community pharmacist services, and resources on display about these services. ${ }^{15}$ When PCPs educate patients about expectations of the community pharmacist's role in their health

Table 1. Best Practice Recommendations for Interdisciplinary Suicide Screening

\begin{tabular}{|c|c|}
\hline Challenge & Recommendations \\
\hline \multirow[t]{3}{*}{ Patients to screen } & $\begin{array}{l}\text { - All adults }(>18) \text { as patients often do } \\
\text { not recognize their symptoms as } \\
\text { signs of mental health conditions } \\
\text { (i.e., depression) }\end{array}$ \\
\hline & $\begin{array}{l}\text { Risk factors for determining suicidal } \\
\text { ideation risk and acuity of risk may } \\
\text { have limited clinical utility }\end{array}$ \\
\hline & $\begin{array}{l}\text { Older adults }(>50) \text {, particularly } \\
\text { men, are less likely to be screened } \\
\text { for suicidal ideation } 37,38\end{array}$ \\
\hline \multirow[t]{4}{*}{$\begin{array}{l}\text { Lack of education } \\
\text { and preparation }\end{array}$} & $\begin{array}{l}\text { To address the suicide public health } \\
\text { crisis, Washington state requires all } \\
\text { health care providers to complete } \\
\text { suicide prevention training }\end{array}$ \\
\hline & $\begin{array}{l}2012 \text { National Strategy for Suicide } \\
\text { Prevention outlined the importance } \\
\text { of prevention training for all } \\
\text { personnel in health professions }\end{array}$ \\
\hline & $\begin{array}{l}\text { Evidence-based suicide prevention } \\
\text { training should be required of all } \\
\text { health care providers, including } \\
\text { pharmacists }{ }^{40}\end{array}$ \\
\hline & $\begin{array}{l}\text { Interprofessional education at } \\
\text { schools and colleges of pharmacy, } \\
\text { medicine, etc., could incorporate } \\
\text { mental health care and access }\end{array}$ \\
\hline \multirow[t]{3}{*}{$\begin{array}{l}\text { Gaps in transitions } \\
\text { of care }\end{array}$} & $\begin{array}{l}\text { Need to develop transitions of care } \\
\text { programs post-emergency } \\
\text { department discharge to } \\
\text { communicate back to PCP, } \\
\text { community pharmacist, and if } \\
\text { established, mental health care } \\
\text { provider }\end{array}$ \\
\hline & $\begin{array}{l}\text { - Need to ensure adequate } \\
\text { psychosocial assessment occurs to } \\
\text { identify patients at risk }\end{array}$ \\
\hline & $\begin{array}{l}\text { - Need to develop triage process } \\
\text { from community pharmacy to PCP/ } \\
\text { mental health care provider or crisis } \\
\text { unit/acute care based on severity }\end{array}$ \\
\hline \multirow[t]{2}{*}{$\begin{array}{l}\text { Role of the } \\
\text { pharmacist }\end{array}$} & $\begin{array}{l}\text { PCPs encourage patient perception } \\
\text { of the pharmacist as part of the } \\
\text { mental health care team }\end{array}$ \\
\hline & $\begin{array}{l}\text { - Research models of interdisciplinary } \\
\text { care for suicide prevention to } \\
\text { identify best practices }\end{array}$ \\
\hline
\end{tabular}

PCP, primary care provider. 
care, the barrier of patient acceptance of an expanded role of the pharmacist is decreased. ${ }^{34} \mathrm{Im}$ proving identification of patients at risk for depression and suicidal ideation is a critical public health concern, and greater collaboration between PCPs and community pharmacists could provide a means to do so.

Looking forward, many questions still need to be answered and require thoughtful use of implementation science and research to identify the best interdisciplinary response to the suicide public health crisis. The National Action Alliance for Suicide Prevention Research Prioritization Task Force developed the first coordinated suicide prevention research agenda in 2014. ${ }^{35}$ Research priorities included provider and gatekeeper training, enhanced continuity of care through generation of models that ensure accessible treatment, and effective care. ${ }^{35}$ Table 1 provides a summary of the author's recommendations for key questions and objectives for stakeholders on how to create an interdisciplinary response to the suicide public health crisis in the United States.

To see this article online, please go to: http://jabfm.org/content/ 32/6/763.full.

\section{References}

1. National Institute of Mental Health. Suicide. Available from: https://www.nimh.nih.gov/health/statis tics/suicide.shtml. Updated May 2018. Accessed May 8, 2019.

2. Smith RC. Educating trainees about common mental health problems in primary care: a (not so) modest proposal. Acad Med 2011;86:e16.

3. U.S. Preventative Services Task Force. Final recommendation statement. Depression in adults: screening. Available from: https://www.uspreventiveservic estaskforce.org/Page/Document/Recommendation StatementFinal/depression-in-adults-screening1. Updated January 2016. Accessed May 08, 2019.

4. American Psychiatric Association. Depression screening rates in primary care remain low. Available from: https://www.psychiatry.org/newsroom/newsreleases/depression-screening-rates-in-primarycare-remain-low. Published February 15, 2017. Accessed May 08, 2019.

5. Harrison DL, Miller MJ, Schmitt MR, Touchet BK. Variations in the probability of depression screening at community-based physician practice visits. Prim Care Companion J Clin Psychiatry 2010;12: PCC.09m00911.

6. LaVito A. Suicide rates are climbing and the CDC says mental illness isn't the only factor to blame. Available from: https://www.cnbc.com/2018/06/07/ suicide-rates-are-climbing-and-mental-illness-isntthe-only-factor.html. Published June 7, 2018. Accessed January 8, 2019.

7. Belluz J. Anthony Bourdain's death is one in a growing public health tragedy. Available from: https:// www.vox.com/science-and-health/2018/6/8/17441330/ anthony-bourdain-suicide-rates-us-cdc. Published June 8, 2018. Accessed May 8, 2019.

8. Case A, Deaton A. Mortality and morbidity in the $21^{\text {st }}$ century. Available from: https://www.brookings. edu/wp-content/uploads/2017/08/casetextsp 17 bpea.pdf. Published 2017. Accessed May 08, 2019.

9. Rubin R. Thanks to Logic's song, the phones at ' $1-800-273-8255^{\prime}$ are ringing off the hook. Available from: https://variety.com/2017/music/news/1800-273-8255-logic-song-suicide-prevention-life line-1202542381/. Published August 30, 2017. Accessed May 08, 2019.

10. Luoma JB, Martin CE, Pearson JL. Contact with mental health and primary care providers before suicide: a review of the evidence. Am J Psychiatry 2002;159:909-16.

11. Moose J, Branham A. Pharmacists as influencers of patient adherence. Available from: https://www. pharmacytimes.com/publications/directions-inpharmacy/2014/august2014/pharmacists-as-influencersof-patient-adherence-. Published August 21, 2014. Accessed May 08, 2019.

12. Kniesner TJ, Powers PH, Croghan TW. Provider type and depression treatment adequacy. Health Policy 2005;72:321-32.

13. Mental Health America. 2017 State of mental health in America-access to care data. Available from: http://www.mentalhealthamerica.net/issues/2017state-mental-health-america-access-care-data. Accessed May 8, 2019.

14. Murphy AL, Martin-Misener R, Kutcher SP, O'Reilly CL, Chen TF, Gardner DM. From personal crisis care to convenience shopping: an interpretive description of the experiences of people with mental illness and addictions in community pharmacies. BMC Health Serv Res 2016;16:569.

15. O'Reilly CL, Wong E, Chen TF. A feasibility study of community pharmacists performing depression screening services. Res Social Admin Pharm 2015; 11:364-81.

16. Painter NA, Kuo GM, Collins SP, Palomino YL, Lee KC. Pharmacist training in suicide prevention. J Am Pharm Assoc 2018;58:199-204.

17. Wilson C, Twigg G. Pharmacist-led depression screening and intervention in an underserved, rural, and multi-ethnic diabetic population. J Am Pharm Assoc 2018;58:205-9.

18. Rosser S, Frede S, Conrad WF, Heaton PC. Development, implementation, and evaluation of a pharmacist-conducted screening program for depression. J Am Pharm Assoc 2008;48:46-51. 
19. Kerner Hare S, Kraenow K. Depression screenings: developing a model for use in a community pharmacy. J Am Pharm Assoc 2008;48:46-51.

20. Knox ED, Dopheide JA, Wincor MZ, Han PK. Depression screening in a university campus pharmacy: a pilot project. J Am Pharm Assoc 2006;48: 502-6.

21. Caley CF, Stimmel GL. Characterizing the relationship between individuals with mental health conditions and community pharmacists. Available from: https://cpnpf.org/_docs/foundation/2012/namisurvey-report.pdf. Published 2012. Accessed January 8, 2019.

22. Knox K, Fejzic J, Mey A, et al. Mental health consumer and caregiver perceptions of stigma in Australian community pharmacies. Int J Soc Psychiatry 2014;60:533-43.

23. Qato DM, Ozenberger K, Olfson M. Prevalence of prescription medications with depression as a potential adverse effect among adults in the United States. JAMA 2018;319:2289-98.

24. Lavigne JE. Suicidal ideation and behavior as adverse events of prescribed medications: an update for pharmacists. J Am Pharm Assoc 2016;56:203-6.

25. Watkins A, McKee J, Hughes C, Pfeiffenberger T. Community pharmacists' attitudes towards providing care and services to patients with severe and persistent mental illness. J Am Pharm Assoc 2017; 57:S217-S224.

26. Giannetti V, Caley CF, Kamal KM, et al. Community pharmacists and mental illness: a survey of service provisions, stigma, attitudes and beliefs. Int J Clin Pharm 2018;40:1096-105.

27. Scheerder G, De Coster I, Van Audenhove C. Pharmacists' role in depression care: a survey of attitudes, current practices, and barriers. Psychiatr Serv 2008; 59:1155-60.

28. Benfield MJ, Mospan C, Gillette C, Pierce B. Community pharmacist attitudes, perceptions, and barriers in performing suicidal ideation assessment. Poster presentation at the 2018 North Carolina Pharmacists Association Annual Meeting, WinstonSalem, NC. North Carolina Pharmacist Journal 2018;98:33-4.

29. Carpenter DM, Lavigne JE, Roberts CA, Zacher J, Colmenares EW. A review of suicide prevention programs and training policies for pharmacists. J Am Pharm Assoc 2018;58:522-9.
30. Morgan AJ, Ross A, Reavley NJ. Systematic review and meta-analysis of Mental Health First Aid training: Effects on knowledge, stigma, and helping behavior. PLoS One 2018;13:e0197102.

31. Mental Health First Aid Australia. MHFA research. Available from: https://mhfa.com.au/mhfa-research. Accessed May 08, 2019.

32. Pharmacy Guild of Australia. Quality care pharmacy program. Canberra, Australia: Pharmacy Guild of Australia; 2014.

33. Winchester BR, Watkins SC, Brahm NC, Harrison DL, Miller MJ. Mental health treatment associated with community-based depression screening: considerations for planning multidisciplinary collaborative care. Ann Pharmacother 2013;47:797-804.

34. Calogero S, Caley CF. Supporting patients with mental illness: deconstructing barriers to community pharmacist access. J Am Pharm Assoc 2017; 57:248-55

35. Claasseen CA, Pearson JL, Khodyakov D, et al. Reducing the burden of suicide in the U.S.: the aspirational research goals of the National Action Alliance for Suicide Prevention Research Prioritization Task Force. Am J Prev Med 2014;47:309-14.

36. Tucker RP, Crowley KJ, Davidson CL, Gutierrez PM. Risk factors, warning signs, and drivers of suicide: what are they, how do they differ, and why does it matter? Suicide Life Threat Behav 2015; 45:679-89.

37. Raue PJ. Physicians are less likely to assess and manage suicide risk among older adults: broader implications for suicide prevention within primary care. Am J Geriatric Psychiatry 2019;27:609-610.

38. Vannoy S, Park M, Maroney MR, Unützer J, Apesoa-Varano EC, Hinton L. The perspective of older men with depression on suicide and its prevention in primary care: Implications for primary care engagement strategies. Crisis 2018;39:397-405.

39. Graves JM, Mackelprang JL, Van Natta SE, Holliday C. Suicide prevention training: policies for health care professionals across the United States as of October 2017. Am J Public Health 2018;108: $760-8$.

40. Murphy AL, Gardner DM, Chen TF, O'Rielly C, Kutcher SP. Community pharmacists and the assessment and management of suicide risk. Can Pharm J (Ott) 2015;148:171-5. 